\title{
Exploring Denial-Correction Pairings in Major Applied Linguistics Textbooks
}

\author{
Babak Majidzadeh $^{1}$, Abdol Majid Hayati ${ }^{2}$ \\ ${ }^{1}$ Department of Teaching English as a Foreign Language, Faculty of Letters and Humanities, Shahid Chamran University of Ahvaz, Ahvaz, \\ Iran \\ ${ }^{2}$ Department of TEFL, Faculty of Letters and Humanities, Shahid Chamran University of Ahvaz, Ahvaz, Iran
}

Email address:

bm49phd@gmail.com (B. Majidzadeh), majid_hayati@yahoo.com (A. M. Hayati)

\section{To cite this article:}

Babak Majidzadeh, Abdol Majid Hayati. Exploring Denial-Correction Pairings in Major Applied Linguistics Textbooks. International Journal of Education, Culture and Society. Vol. 2, No. 1, 2017, pp. 20-32. doi: 10.11648/j.ijecs.20170201.14

Received: November 27, 2016; Accepted: January 24, 2017; Published: March 2, 2017

\begin{abstract}
Denial and correction as a subcategory of basic clause relations is of crucial importance in a host of research in written textual analysis. Yet investigating potential various patterns construing denial-correction pairing has long been neglected. Following Pagano (2004) and Winter's (2004) ideas concerning denials, the current study aimed to investigate dcpairing patterns in a corpus of textbooks in Applied Linguistics taught at MA and PhD levels. The study revealed the existence of 12 patterns that were frequently used in the corpus. It was also found that there was a significant difference between dcpairing patterns used in the MA and the PhD textbooks in terms of the frequency of the use of the patterns. The study also found other functions for dc-pairing patterns in the corpus.
\end{abstract}

Keywords: Denial-Correction Pairings, Heteroglossia, Contractive, Existential Paradigm

\section{Introduction}

Denial and correction as a subcategory of basic clause relations is largely investigated by Winter (2004) [24]. As an integral part of the text structure, Winter states that denial and correction are a fundamental part of the rhetoric of argument, where you offer what is true for what you are denying as true. This relation was first described by Poutsma [19] (1926-9, p. 157, cited in Winter, 2004, p. 50, [24] as Substitutive Adversative Co-ordination) [24]. As Winter exemplifies, one type of denial is indicated by the negator 'not' and the correction by the replacement or change of a part of the clause, as in: 'the bee didn't get tired - it got dead' [24], where the adjective 'tired' is replaced by the adjective 'dead', which corrects it.

In line with denials, Winter states that it is also possible to deny an idea and then use the co-ordinator ' $b u t$ ' to express an unexpected change [24]. As an example from the corpus, “... a communicative function ... does not depend on the grammatical and discoursal features of a function but on the purpose and context of communication" [14], where the correction clause is "but on the purpose and context of communication".
Although negation has been traditionally studied from morphological, syntactic and logical points, relatively few studies have investigated its semantic, pragmatic aspects; that is, its use or meaning in context. Tottie $(1982,1987)$ [20], [21] in an attempt to systemize the uses of negation classified them as rejections (including refusals) and denials. She claims that the main difference between a rejection and a denial is that the former expresses the sender's volition as in: "A: Would you care for a drink? B: No, thanks."; whereas the latter does not. A denial is concerned with facts and just states that an assertion is not true, as in: A: So you are still living out there. B: No, I am not. I have rented a flat near the bank [18].

Looking at negation from a Systemic Functional Linguistics vantage point, Pagano (2004) [18] tried to investigate it with a focus on its ideational and interpersonal functioning. Leveling a criticism against Tottie's (1982, 1987) [20], [21] classification of the uses of negatives in both oral and written language, she asserted that Tottie's explanation was not satisfactory. There is more than just volition to both denial and rejection. Contrary to what Tottie 
claims, a denial may also involve volition. Pagano states that it is not volition, rather the predominant function that determines the kind of negation. On the basis of language metafunctions in SFL, an utterance can have a textual, an ideational and an interpersonal function; therefore, Pagano asserts that it is the predominant function that defines the utterance as refusal or denial. When the interpersonal function predominates, it is a rejection, whereas if the predominant function is ideational, it is considered a denial, though it may carry an interpersonal meaning as well [18].

In the following conversation from Pagano (2004) [18], B denies what $\mathrm{A}$ has assumed, and the denial contains a strong ideational meaning as B intends to correct A's assumption. Therefore, "the correctness of the fact is more relevant than the interpersonal element" [18] A: So you are still living out there. B: No, I am not. I have rented a flat near the bank.

Although any constituent of a clause such as a subject, verb, object of preposition or an adjective can be denied, replaced and corrected by what the writer holds true /correct, we cannot deny just anything. What is denied has to be a member of the set of choices a speaker has in a given context in the form of either an existential paradigm or schemata.

Miller and Johnson-Laird (1976) [17], observed that what is denied has to be plausible or acceptable in the context of interaction. They borrowed the term from Brazil (1985) [2], which means a group of linguistic items that belong to the shared experience or understanding in a given context and can substitute each other [18]. In addition to existential paradigm, what is denied originates from schemata or the "packets of information stored in memory representing general knowledge about objects, situations, events or actions" [3]. Since schemata are culture-specific, they differ from one culture to another. That is, what is denied and rejected in one culture may be quite acceptable in another culture.

Following Tottie's (1987) [21] classification of denials into implicit and explicit ones, Pagano (2004) [18] just focused on selecting implicit denials in the written texts. That is, she studied "negatives in which the proposition denied did not appear in the text" [21]. Based on such ideas, Pagano classified denials into four groups [18] as the denials of:

a) background information; denials of the reader's certain mistaken ideas based on his previous background knowledge. It was the most common denial in her data as: "A text is a semantic unit, not a grammatical one. But meanings are realized through wordings... (Halliday 1994: xvii) [7] b) text-processed information; denials of an erroneous inference based on the text, as in: "It has been estimated that nearly $50 \%$ of .... However, these figures do not necessarily mean a ...". c) unfulfilled expectations; as in: "This article attempts not grand solutions but rather a clarification of some of the theoretical differences between ...". d) contrasts; denials to contrast two or more items, as the differences between the past and the present in: "For past generations, lifestyle was .... They had no antibiotics, no cures for infectious disease."

In her study of negation, Pagano ascribed the source of denials to existential paradigm and schemata. However, the meaning of every sentence "is [also] a function of its adjoining sentences" [24], particularly those which immediately precede it; that is, we interpret the meaning of a clause or group of clauses in the light of their adjoining clauses or group of clauses. On the one hand, Winter (2004) [24] asserts that prior to reading the text the audience, "brings their knowledge" [24] to the text to fill in the missing information, and on the other hand, Widdowson (1979) [22] believes that in writing a text it is the writer who "thinks of the reader's possible reactions, anticipates them and acts accordingly." That is, although no physical interlocutor is present in a text, the writer imagines and creates "a mental representation of the reader", then attributes to this reader certain experience, knowledge, opinions or beliefs, and builds his/her message [18].

In this regard, and in addition to existential paradigm, schemata, the writer's anticipation of the reader's possible reactions, the writer-reader interaction, and Pagano's classification of denials, there is a crucial concept proposed by Bakhtin. Bakhtin (1981) [1], observes that all utterances exist "... against a backdrop of other concrete utterances on the same theme, a background made up of contradictory opinions, points of view and value judgments... pregnant with responses and objections" [1]. That is to say, a dialogistic perspective reveals that when writers engage with prior speakers and prior utterances in the same sphere, they can stand with, stand against, be undecided, or neutral to the other speakers and their value positions. At the same time, the dialogistic perspective reveals the anticipatory aspect of the text that equips the writer with the signals for the ways they expect their addressee to respond to the current proposition. Moreover, this reflects Bakhtin's notions of dialogism and heteroglossia under which all verbal communication, whether written or spoken, is 'dialogic' in that to speak or write always refers to or reveals the influence of, what is written before, and simultaneously anticipates the reader's responses [16]. Utterances are categorized accordingly into a two-way distinction that classifies them as 'monoglossic' or 'heteroglossic. When they make no reference to other voices or viewpoints, they are monoglossic, whereas when they invoke or allow for dialogistic alternatives and refer to other voices or viewpoints, they are heteroglossic [16].

When no room is left for alternative viewpoints, the proposition is monoglossically declared. They have no dialogistic alternatives to be recognized or engaged with. On the other hand, if the writer goes on to supply a series of arguments to support the value position, or if it is presented as uttered by others it is heteroglossic. For instance, the proposition that "... [Chomsky] is interested in looking at human language as a cognitive psychological mechanism and not as a communicative tool for social interaction. ... Halliday ... preferred to define meaning potential not in terms of the mind but in terms of the culture..." [14], construes Chomsky's proposition as very much at issue and the value position becomes the focus of a debate in further 
argumentation. The proposition is thus heteroglossically declared [16].

On the basis of their inter-subjective functionality, heteroglossic resources can be divided into two broad categories as dialogically expansive or dialogically contractive. Martin and White (2005) [16] state that dialogic expansion occurs when the propositions consider, contain or make allowances for dialogically alternative positions and voices. That is, dialogic space is opened up for alternative positions [16]. Alternatively, when the propositions challenge, fend off or restrict the scope of such alternative positions and voices, dialogic contraction is at work. That is, it closes down the space for dialogic alternatives and does not allow other views to enter into the play.

As a sub-category of heteroglossia, disclaim positions the textual voice as rejecting or being at odds with another contrary position, and it acts to contract the dialogic space. Although it construes a dialogistic backdrop for the text of other voices and value positions, it is maximally contractive as it excludes certain dialogic alternatives. In other words, via disclaim the dialogic alternative is directly rejected, replaced or held to be not applicable [16]. Disclaim is of two types: negation and concession/ counter-expectation:

- (deny) negation (You don't need to practice all the materials via choral repetition.)

- (counter) concession/counter-expectation (Although they practiced the grammar point chorally, the students still had problems using it.)

Part of the focus of the current study is on negation rather than counter-expectation. Therefore, an account of negation is presented below. In dialogistic terms, "the negative is not the simple logical opposite of the positive, since the negative necessarily carries with it the positive, while the positive does not reciprocally carry the negative" [16]. Negation introduces an alternative positive position into the dialogue, which is then rejected. The denial enters into a dialogue so as to respond to wrong claims/beliefs. For instance, [There is nothing wrong with...] is dialogically responding to the false claim that [there IS something wrong with] [16].

In denial, there is a disalignment with some third party (to indicate that this is not the case) or the denial is against the putative addressee. The writer assumes that the audience will have some wrong beliefs; therefore, he intends to correct the misunderstanding or misconception on the addressee's part. Here, the addresser presents himself as having greater expertise so as to adjust the communication with the addressee [16]. Nevertheless, all correction must be within the existential paradigms, with a set of shared and substitutable aspects for the entity [18]. That is, a writer cannot deny just anything, but only assumptions which are "plausible or acceptable in the context of interaction" [18] or "the propositions which are experientially possible in that context" [18], but not all the linguistically possible denials that can be produced.

Although negation has been explored from different perspectives, there is little work on how the expression of denial-correction pairings may vary in particular genres and contexts, and our knowledge of how the pairing is expressed is likewise very limited. Parallel with an advocacy for conducting more research, there is room for examining the ways scientists verbalize their denial-correction pairings in the context of particular genres. Therefore, it is the main goal and purpose of the current corpus-based study to explore the lexico-grammatical structures that realize denial-correction pairings in major Applied Linguistics textbooks. These are the most prominent textbooks of Applied Linguistics written by native speakers of English, recommended by a number of informant Iranian professors, taught at the tertiary level of education, and scrutinized as the main source texts for the $\mathrm{MA}$ and $\mathrm{PhD}$ students majoring in TEFL in Iran. The recommended textbook for the MA level is Understanding Language Teaching (Kumaravadivelu, 2008, abbreviated as ULT) [14] and for the $\mathrm{PhD}$ level is Input, Interaction, and Corrective Feedback (Mackey, 2012, abbreviated as ICF) [15].

This corpus-based study, therefore, aimed to address the question of the lexico-grammatical patterns to realize and indicate denial-correction pairings and the various functions served by deploying such patterns in $\mathrm{AL}$ textbooks. To achieve this end, the following research questions stand out:

1) What are the recurrent patterns to indicate denialcorrection pairings in major Applied Linguistics textbooks at MA and $\mathrm{PhD}$ levels of tertiary education?

2) What are the different functions served by the denialcorrection pairings in major Applied Linguistics textbooks?

3) What are the corresponding distribution and frequencies of denial-correction pairings in the corpus of major Applied Linguistics textbooks at MA and PhD levels and how do they compare?

In what follows the materials, procedure for conducting the study, the qualitative and quantitative analyses, are presented. All this is followed by the results of the study accompanied with the relevant discussion. Finally, the conclusion section sums up the major findings of the current study.

\section{Methodology}

This study is grounded in both Winter (2004) [24] and Pagano's (2004) [18] conception of denial and correction structures. The research design for the current study is Sequential Mixed-Methods approach, beginning with a qualitative analysis for exploratory purposes followed up with a quantitative analysis. Using the structure of sentence as advocated by Eggins (2004) [6] in SFL, the researchers first explored the underlying lexico-grammatical structures for the instantiation of denial-correction pairing patterns in Applied Linguistics textbooks, their corresponding distribution and finally the functions potentially served by the denial-correction pairings. 


\subsection{Materials}

A representative sample of textbooks in Applied Linguistics (AL) was selected. Textbook selection, in the present study, met the following criteria: A number of informants in the discipline were asked to recommend textbooks they considered as essential in AL, which had been established as major course books at higher levels of tertiary education (i.e., at $\mathrm{MA}$ and $\mathrm{PhD}$ levels) in the discipline. The materials were selected from applied linguistics textbooks. The selection was motivated with the aim of building the materials representative of Applied Linguistics books taught in Iranian universities at MA and $\mathrm{PhD}$ levels. Decision on the selection of each book was made by consulting 10 experts in the discipline. To this aim, e-mails were sent to the university professors at Tehran, Isfahan, and Tabriz Universities, and they were requested to recommend the most key textbooks for MA and PhD levels in the discipline. Different books were suggested by these experts, and their suggestions were, then, compared and contrasted to arrive at a final decision on the selected materials for the analysis. Based on the recency of publication, the formality, the content, and the author of the books, only one major textbook for each level was selected as the material for analysis. Accordingly, the recommended AL textbook for the MA level was represented by Understanding Language Teaching (Kumaravadivelu, 2008, abbreviated as ULT) [14] and for the PhD level was exemplified by Input, Interaction, and Corrective Feedback (Mackey, 2012, abbreviated as ICF) [15].

\subsection{Instrumentation}

The main concept of the quest for dc-pairings was based on denial as advocated by Pagano (2004) [18], and the juxtaposition of the denial and correction to make up a pairing as introduced by Winter (2004) [24]. In addition to the study of denials, part of Bakhtin's (1981) [1] ideas concerning heteroglossia was also taken into consideration.

\subsection{Procedure}

Because the present study was to investigate the various patterns of denial-correction pairings, the sentences with just denials but no corrections were excluded from the study. In this regard, the unit of analysis in the study was sentence, as demarcated by Halliday and Matthiessen (2004) [8] and Eggins (2004) [6]. That is to say, various types of clauses whether simple, compound with paratactic relations, complex with hypotactic relations (i.e., clause simplexes and clause complexes), which Eggins (2004) [6] collectively defines as sentence were the unit of analysis. The main reason for a sentence as being the unit of analysis was that denialcorrection pairings occur both in dependent and independent clauses. The selected textbooks were analyzed from cover to cover. Analysis began with reading the texts carefully twice to ensure the comprehension of the content. In the first step, the dominant patterns of denial-correction pairings (i.e., a denial immediately followed/preceded by correction), were identified and extracted. The lexico-grammatical structures and patterns were recorded and tallied. In the second step, the texts were scrutinized to identify and record the frequency of occurrence for each dc-pairing. At this stage, both the emerging dc-pairing patterns and the corresponding frequencies were tabulated. In the third step, which was after about a two-week interval, the researchers re-examined the data separately.

As a response to the subjective reading problem faced by all text-based research, and in order to increase the reliability [5] of the current study (i.e., to validate our own reading interpretation), and to ensure that instances of denial-correction pairings were identified with high degree of accuracy, inter-rater and intra-rater procedures were implemented: Working independently, a second nonnative rater who specializes in SLA research also analyzed the sentences, double-checked a sample to determine the coder reliability and then we agreed on the method of analysis. In other words, based on the concept of denial-correction pairings, the two raters analyzed samples of sentences independently twice with an interval of two weeks.

For each rater, the intra-rater reliability was calculated. Subsequently, to improve and ensure the inter-rater reliability of the analyses, the second nonnative rater analyzed a sample of the sentences in the corpus independently, extracted the patterns, and recorded the corresponding frequencies. Minor discrepancies in the analyses were negotiated. In order to obtain the index of inter-rater reliability, the Kappa coefficient was then computed. For this stage, the selection of the samples was purposeful rather than random.

In the fourth step, to identify textbook writers' preferences for encoding denial-correction pairings, the distribution, the total frequency and percentage of different structures that instantiated denial-correction pairings were compared to detect the possible differences among them and to see whether or not the differences were significant. At this stage, Chi square was calculated to detect the possible differences in the use or frequency of the patterns in MA versus $\mathrm{PhD}$ textbooks. What follows deals with the qualitative and quantitative analyses of the materials.

\section{Corpus Analysis}

\subsection{Qualitative Analysis}

At the qualitative end of the approach, the study sought to examine the issue, developed from the data, of the recurring patterns that realized denial-correction pairings. In other words, the qualitative stage of the exploratory investigation focused on text analysis in terms of the quest for recurrent lexico-grammatical structures that contained denialcorrection pairings amongst the sentences in the two corpora (i.e., at MA and $\mathrm{PhD}$ textbooks).

Given the possibility of variation in terms of the lexicogrammatical elements that realize dc-pairings across different sections of each textbook, a pilot study was conducted, and the data were analyzed until the researcher could identify dominant patterns and functionality of 
denial-correction pairings in each and every section of the textbooks. The analysis was carried on until no more patterns or functions emerged and the researcher could identify no other dominant markers, patterns or functionalities for the structures in the textbooks. For the pilot study, after finding the markers of denial-correction pairings, delineating them in their categories, and also finding their functions in the sample, the whole process was conducted for the second time to render coding reliability. In other words, the researcher re-analyzed a sample from the corpus within an interval of at least two weeks to control intra-rater (coding) reliability.

The sentences in the corpus were carefully studied, focusing on the propositional meaning, their stance in the context and content in presenting ideas and constructing knowledge. All this was carried out to have a good grasp of what the text semantically and pragmatically was about as well as checking the interconnection between sentences and ideas. In the quest for structures that realized denialcorrection pairings, each sentence was meticulously focused on to explore the kind of lexico-grammatical structures that instantiated denial-correction pairings, the connection to the preceding and proceeding sections and sentences, as at times one element of the pairing was in a sentence, whereas the other element was in the following one (See examples $31 \&$ 32 below). This was achieved through:

(i) identifying the elements and structures construing dcpairing in which instances of both denial of the false idea were juxtaposed with the correction for the denial.

(ii) exploring the nature and functionality of the emerging patterns of denial-correction pairings.

In both textbooks, there were patterns in which denialcorrection pairings occurred. In other words, at the qualitative phase, the corpus was analyzed to find the following cases. In what follows, the patterns from each textbook are exemplified in order of frequency (i.e., from high to low). It should be noted that in both text types, pattern one (i.e., A rather than B) was more prevalent than other patterns of denial-correction pairings:

\section{Pattern 1: A rather than $B$}

(1) ... interaction is still better thought of as an approach rather than as a theory of SLA. [15]

(2) ... experience immediate improvements in L2 comprehension rather than in L2 production. [15]

(3) ... this modification makes the task closed rather than open.[15]

(4) $\ldots$ directed our attention to the process of learning rather than to the product of teaching, ... [14]

Pattern 2: $A$, not $B$

(5) Because of the active involvement of the learner in the learning process, only meaningful learning, not rote learning, can lead to internalization of language systems [14]

(6) “... while sciences have advanced by approximations in which each new stage results from an improvement, not rejection, of what has gone before, language-teaching methods have followed the pendulum of fashion from one extreme to the other" [14]

(7) "Notice that I call these intake factors facilitating, not causal, factors.[14]

(8) ... it should be borne in mind that we are talking about learning opportunities, not guarantees. [15]

(9) TBLT focuses on learning by doing and takes the position that tasks, not skills, are the unit of analysis. (italics in the original) [15]

(10) ... transitory (i.e., drawing attention to itself only for a moment _ not for as long as systematic correction does).[14]

(11) “... language is best taught when it is being used to transmit messages, not when it is explicitly taught for conscious learning"[14]

(12) Language development is comprehension based, not production based.[14]

(13) "This concept of function would lead to a renewed emphasis on grammar, not to its neglect" [14]

(14) Thus, for cognitive psychologists, mental processes underlying response is important, not the response itself. [14]

(15) ... consciousness raising is the means to an end, not the end itself.[14]

Pattern 3: not A, but B

(16) ... the development of L2 knowledge/ability is not a linear, discrete, additive process but a cyclical, holistic process consisting of several transitional and parallel systems [14]

(17) ... when learners are not under communicative or cognitive pressure by engaging in feedback and response exchanges, but are simply observing it with their peers, they might be more fully able to process the feedback, and learn from it. [15]

\section{Pattern 4: A, but not B}

(18) ... classroom contexts have often, but not always, zeroed in on corrective feedback,....[15]

(19) ... we did note that an increase in the production of higher-level questions was found on both the immediate and delayed post-tests, a result which contrasted with previous studies that found delayed, but not immediate effects for adults. [15]

(20) ... WM capacity significantly predicted the effects of recast, but not metalinguistic feedback, on the acquisition of the English that-trace filter. [15]

(21) "You've left the door open!" could serve as a directive from teacher to pupil, but not from teacher to principal.[14]

Pattern 5: not A; rather $B$

(22) ... [input] is not assumed to be sufficient for SLA on its own; rather, the ways in which learners interact .... are at the heart of the interaction approach. [15]

(23) The arrows connecting input and output ... suggest that learner output is not a terminal point; it is rather a part in a cycle serving as an important source of input data for the learner thereby affecting the course of L2 
development.[14]

(24) This does not mean that the profession has reached a dead end; rather, it means that the profession has completed yet another phase in its long, cyclical history of methods, and has just set sail in uncharted waters.[14]

Pattern 6: not A, but rather $B$

(25) ... acquisition is supported not by the modifications themselves but rather by the negotiations for meaning ...[15]

(26) This may not reflect a fault of negotiation, but rather the current state of research instruments. [15]

(27) ... the focus of CTP was not on "communicative competence" in the sense of achieving social or situational appropriacy, but rather on "grammatical competence" itself.[14]

Pattern 7: $A$ and not $B$

(28) Any correction that takes place should be incidental and not systematic.[14]

Pattern 8: not $A$; $B$

(29) Task is not a methodological construct; it is a curricular content. [14]

(30) The terms principles and procedures are not new; they are implicit in the literature and are being used widely ...[14]

Pattern 9: not A. Rather $B$

(31) ... interaction research is not intended to be seen as a complete, causal theory of SLA. Rather, interaction can be regarded as a facilitator of ...[15]

(32) "... whatever it is that is raised to consciousness is not to be looked upon as an artifact or object of study to be committed to memory by the learner and thence recalled by him whenever sentences have to be produced. Rather, what is raised to consciousness is not the grammatical product but aspects of the grammatical process"[14]. In this example, the sentence initiated with Rather, contains a "not A but B" pairing (Pattern 3) as well.

Pattern 10: $A$; not $B$

(33) Clearly, the speaker-hearer Chomsky is talking about is an artificially constructed idealized person; not an actual language user.[14]

Pattern 11: not $A, B$

(34) "the importance of interaction is not simply that it creates learning opportunities, it is that it constitutes learning itself'"[14]

Pattern 12: Rather than A, B

(35) Rather than age of acquisition, Birdsong found the subjects age at their arrival in France to be correlated with their attainment,... [15]

(36) Rather than comparing and making claims about the superiority of ..., offering information about the utility and ..., might be a more productively helpful way ...[15]

Overall, the order of denial and correction was based on the following general rule:

In all but 1 and 12 , the patterns contained denials as preceded by not. For patterns 1 and 12, denials were preceded by rather than. However, regardless of such a general rule, the correction was always immediately juxtaposed with the denial, either pattern-initially, or patternfinally.

\subsection{Quantitative Analysis}

At the quantitative end, numeric information was gathered to yield statistical data. That is, the quantitative stage conducted statistical analysis in terms of distribution, frequency of the occurrence for such structures and the corresponding percentages in proportion to the total number of cases/occurrences in the corpus. The first stage of the analysis involved a manual search for the instances of acts encoding denial-correction pairings in the corpus.

In light of the study of negatives (Pagano, 2004) [18] and denial-correction as one kind of basic clause relation [24], all instances of denial-correction pairings in the corpus, were detected and recorded. As a response to the subjective reading problem faced by all text-based research, and in order to increase the reliability [5] of the current study (i.e., to validate our own reading interpretation), and to ensure that instances of denial-correction pairings were identified with high degree of accuracy, inter-rater and intra-rater procedures were implemented in the second stage: Working independently, a second rater who specializes in SLA research simultaneously double-checked a sample to obtain the coding reliability. In other words, the two raters analyzed samples of sentences independently twice with an interval of two weeks.

For each rater, the intra-rater reliability was calculated. The reliability indices were 0.93 and 0.89 for the first and the second rater, respectively. Subsequently, to improve and ensure the inter-rater reliability of the analyses, the second non-native rater who specializes in SLA research analyzed a sample of the sentences in the corpus independently, extracted the patterns, and recorded the corresponding frequencies. Minor discrepancies in the analysis were negotiated. In order to obtain the index of inter-rater reliability, the Kappa coefficient was then computed. For this stage, the selection of the samples was purposeful rather than random. The Kappa coefficient was 0.91 , which rendered a high degree of agreement between the two raters.

To identify textbook writers' preferences for encoding denial-correction pairings, the distribution, the total frequency and percentage of different structures that instantiated denial-correction pairings were compared to detect the possible differences among them and to see whether or not the differences were significant. At this stage, Chi square was calculated to detect the possible differences in the use or frequency of the patterns in $\mathrm{MA}$ and $\mathrm{PhD}$ textbooks.

The frequency corresponding to each of the patterns identified in the corpus are presented in the following table: 
Table 1. Total distribution of denial-correction pairing patterns in the corpus $(M A+P h D)$.

\begin{tabular}{llll}
\hline \multirow{2}{*}{ Denial-correction pairing } & \multicolumn{2}{l}{ the Whole Corpus } \\
\cline { 3 - 4 } & & Frequency (F) & Percentage (\%) \\
\hline 1 & A rather than B & 65 & 34 \\
2 & A, not B & 35 & 18 \\
3 & not A, but B & 31 & 16 \\
4 & A, but not B & 16 & 8 \\
5 & not A; rather B & 10 & 5 \\
6 & not A, but rather B & 12 & 6 \\
7 & A and not B & 6 & 3 \\
8 & not A; B & 5 & 3 \\
9 & not A. Rather B & 7 & 4 \\
10 & A; not B & 2 & 1 \\
11 & not A, B & 2 & 1 \\
12 & Rather than A, B & 3 & 2 \\
Total & & 194 & 100 \\
\hline
\end{tabular}

Overall, there were 194 instances of denial-correction pairing in the corpus when all the instances in the two books were considered together. They made up 12 different recurring patterns in the textbooks, though some were specific to one level only; that is, either MA or $\mathrm{PhD}$, rather than both of them. As shown in Table 1, the most frequently used pattern was that of Pattern 1 "A rather than B", whereas the least frequent one was that of Pattern 11 "not A, B" in the corpus. In other words, more than 65 out of 194 instances belonged to Pattern 1 "A rather than B", but only 2 cases were accompanied with Pattern 11 "not A, B", which shows the authors preference to use "A rather than B" as the most common denial-correction pairing.

When considered separately, as evinced in Table 2 below, there were two patterns specifically used in the textbook for MA, but were absent in that of PhD. One was Pattern 7 "A and not B" (See example 28, above) and the other one was Pattern 10 "A; not B" (as exemplified in 33 above). On the contrary, the pattern specifically used in $\mathrm{PhD}$ textbook was Pattern 12 "Rather than A, B" (examples 35 and 36, above), which initiated the sentence, yet it was never an option to be opted for by the writer of the MA textbook.

The writer of the MA textbook utilized a greater number of dc-pairing patterns than that of the $\mathrm{PhD}$ textbook; that is, 146 cases versus 48 cases, respectively. The analysis of the statistics was done using Chi-square to compare frequencies. Because the value of the Chi-square obtained for the use of dc-pairing patterns was far more than the critical value (3.84) with one degree of freedom $(d f=1, p<0.05)$, (See Table 3 below), the difference between the two corpora was meaningful. In other words, there was a statistically significant difference between denial-correction pairing patterns used in the MA and the $\mathrm{PhD}$ textbooks in terms of the frequency of the use of the patterns. Therefore, the answer to the first question of the study was provided by the 12 distinct patterns.

Table 2 also reveals the most and the least denialcorrection pairing patterns used in the corpora for MA and $\mathrm{PhD}$, respectively. Pattern 1 (i.e., A rather than $\mathrm{B}$ ) was extremely common in the textbooks. Pattern 2 (i.e., A, not B) and Pattern 3 (i.e., not A, but B) ranked second and third in order of frequency in the two textbooks. And finally, Patterns 10 and 11 (i.e., "A; not B"; "not A, B") were very scant in the two texts for analysis. The results marked Pattern 1, 2 and 3 to be characteristic of academic discourse represented by ULT and ICF.

Table 2. Distribution of denial-correction pairings in the two corpora (MA vs. $P h D)$.

\begin{tabular}{llllll}
\hline \multirow{2}{*}{ Denial-correction pairing } & \multicolumn{2}{l}{ MA textbook } & \multicolumn{2}{l}{ PhD textbook } \\
\cline { 3 - 6 } & (F) & $(\%)$ & $(\mathbf{F})$ & $(\%)$ \\
\hline 1 & A rather than B & 49 & 34 & 16 & 33 \\
2 & A, not B & 29 & 20 & 6 & 13 \\
3 & not A, but B & 26 & 18 & 5 & 10 \\
4 & A, but not B & 11 & 8 & 5 & 10 \\
5 & not A; rather B & 8 & 5 & 2 & 4 \\
6 & not A, but rather B & 7 & 5 & 5 & 10 \\
7 & A and not B & 6 & 4 & 0 & 0 \\
8 & not A; B & 4 & 3 & 1 & 2 \\
9 & not A. Rather B & 3 & 2 & 4 & 8 \\
10 & A; not B & 2 & 1 & 0 & 0 \\
11 & not A, B & 1 & 1 & 1 & 2 \\
12 & Rather than A, B & 0 & 0 & 3 & 6 \\
\multicolumn{1}{l}{ Total } & & 146 & 100 & 48 & 100 \\
\hline
\end{tabular}

As shown in tables 1 and 2, the first three patterns made up the relatively highest number of occurrences in the two corpora (i.e., $\mathrm{MA}$ and $\mathrm{PhD}$ textbooks) in terms of their frequencies. The first pattern comprised $34 \%$ of the total number of occurrences (i.e., 194) for all the patterns in the whole corpus (i.e., MA $+\mathrm{PhD}$ ). By the same token, the second and the third patterns made up $18 \%$ and $16 \%$ of the total number of occurrences in the whole corpus, respectively. Owing to the fact that the number of pages comprising each textbook was totally different, it is evident that the number of occurrences for the patterns in each book had to be different. Therefore, to compare the distribution of the occurrences of dc-pairings in the two corpora, it was statistically necessary to have an equal number of units of analysis for each textbook. To this end, the frequencies were normalized for 1000 sentences. In other words, in order to be consistent in our analysis, the data were normalized afterwards because the number of clauses in each book (representing the two different levels of higher education as $\mathrm{MA}$ and $\mathrm{PhD}$ levels) was different. In what follows, the results of the quantitative analysis and the related discussion are presented.

\section{Results and Discussion}

The current study was conducted to explore the various patterns of denial-correction pairing in major Applied Linguistics textbooks written by native speakers of English and studied by students of TEFL at MA and PhD levels in Iran. The patterns emerging from the corpus are shown in Table 3 after normalizing the data. In order to find out the similarities and differences in the two corpora in terms of the frequency of occurrence for the patterns, one-way Chi-square 
was computed for each pattern. As a one-way $X^{2}$ with only one degree of freedom was involved in the analysis, an adjustment known as Yates correction for continuity was employed. Therefore, the estimate for the patterns was corrected by applying Yates correction factor so that they could fit the $X^{2}$ distribution [9]. Therefore, for the first pattern (i.e., A rather than B), Chi Square $\left(X^{2}=18.28\right)$ was far more than the critical value (3.84) with one degree of freedom $(d f=1, p<0.05)$, and the difference between the two textbooks was meaningful. In other words, there was a significant difference between denial-correction pairing patterns used in the MA and the PhD textbooks in terms of the frequency of the use of this pattern (See Table 3 below).

Table 3. The comparison of the two groups in their use of dc-pairing patterns after applying Yates correction factor (normalized for 1000 sentences).

\begin{tabular}{|c|c|c|c|c|c|c|c|c|c|c|}
\hline & \multirow{2}{*}{ Denial-correction pairing } & \multicolumn{2}{|c|}{ MA } & \multicolumn{2}{|c|}{ PhD } & \multirow{2}{*}{$\mathbf{E}$} & \multirow{2}{*}{ (O-E)-0.5 } & \multirow{2}{*}{$(\mathrm{O}-\mathrm{E}-0.5)^{2}$} & \multirow{2}{*}{$(\mathrm{O}-\mathrm{E}-0.5)^{2} / \mathrm{E}$} & \multirow{2}{*}{$X^{2}$ Chi-sq. } \\
\hline & & $\mathbf{F}$ & $(\%)$ & $\mathbf{F}$ & $(\%)$ & & & & & \\
\hline 1 & A rather than $B$ & 38 & (37) & 8 & (24) & 23 & 14.5 & 210.25 & 9.14 & 18.28 \\
\hline 2 & $\mathrm{~A}, \operatorname{not} \mathrm{B}$ & 24 & (24) & 5 & (15) & 14.5 & 9 & 81 & 5.59 & 11.17 \\
\hline 3 & not $A$, but B & 16 & (16) & 5 & (15) & 10.5 & 5 & 25 & 2.38 & 4.76 \\
\hline 4 & A, but not B & 7 & (7) & 3 & (9) & 5 & 1.5 & 2.25 & 0.45 & 0.90 \\
\hline 5 & not $\mathrm{A}$; rather $\mathrm{B}$ & 5 & (5) & 2 & (6) & 3.5 & 1 & 1 & 0.29 & 0.57 \\
\hline 6 & not $\mathrm{A}$, but rather $\mathrm{B}$ & 5 & (5) & 4 & (12) & 4.5 & 0 & 0 & 0.00 & 0.00 \\
\hline 7 & $A$ and not $B$ & 2 & (2) & 0 & (0) & 1 & 0.5 & 0.25 & 0.25 & 0.50 \\
\hline 8 & $\operatorname{not} \mathrm{A} ; \mathrm{B}$ & 2 & (2) & 1 & (3) & 1.5 & 0 & 0 & 0.00 & 0.00 \\
\hline 9 & not A. Rather B & 2 & (2) & 2 & (6) & 2 & -0.5 & 0.25 & 0.13 & 0.25 \\
\hline 10 & $\mathrm{~A} ; \operatorname{not} \mathrm{B}$ & 1 & (1) & 0 & (0) & 0.5 & 0 & 0 & 0.00 & 0.00 \\
\hline 11 & $\operatorname{not} \mathrm{A}, \mathrm{B}$ & 0 & (0) & 1 & (3) & 0.5 & 0 & 0 & 0.00 & 0.00 \\
\hline 12 & Rather than A, B & 0 & (0) & 3 & (9) & 1.5 & 1 & 1 & 0.67 & 1.33 \\
\hline \multicolumn{2}{|c|}{ Total } & 102 & & 34 & & & & & & \\
\hline
\end{tabular}

$\mathrm{P}<.05$, d.f. $=1, \mathrm{O}=$ observed, $\mathrm{E}=$ Expected, critical value $=3.84, X^{2}=\sum(\mathrm{Fo}-\mathrm{Fe}-0.5)^{2} / \mathrm{E}=$ Chi-square observed

Further scrutiny into the textbooks marked preference for coding dc-pairing patterns by the writers, revealed the first three patterns (i.e., "A rather than B"; "A, not B"; "not A, but $B$ ") as the most frequently used ones, whereas the rest of the patterns were kept in low profile (i.e., patterns 4 through 12). The data presented in Table 3 show the total frequency and percentage of different types of dc-pairing patterns used in textbooks written for the MA and PhD levels, respectively:

Although the denial-correction pairings numerated as 4, 5, 6,8 , and 9 in the table, were differently used by the authors in the corpus in terms of their frequencies, none was significantly different from the corresponding counterpart. In other words, there was no statistically significant difference in the use of these patterns at the two levels. Therefore, the two textbooks were similar in the use of the patterns 4 through 11. Moreover, although the Chi Square obtained for pattern 12 was not zero as was the case for the patterns 6,8 , 10 and 11 , it was much smaller than the critical value (3.84) to indicate any statistical difference. In other words, the differences between the frequencies for these patterns at the two levels were not statistically significant.

However, there was a clear difference in the frequencies of the first three patterns. To ensure the statistical significance of the apparent difference, Chi Squares were computed once for the patterns taken together (See table 4), and once for each row; that is, a) A rather than B, b) A, not B, and c) not A, but B, respectively (See table 5).

Table 4. The comparison of the two groups in their overall use of the first three dc-pairing patterns (Normalized for 1000 sentences) $P<.05 d . f .=1$.

\begin{tabular}{llllll}
\hline O for MA & O for PhD & E & (Fo-Fe-0.5) Yates Correction & (Fo-Fe-0.5) $^{\mathbf{2}}$ & $\sum(\mathbf{F o}-\mathbf{F e}-\mathbf{0 . 5})^{2} / \mathbf{E}$ \\
\hline 78 & 18 & 48 & 29.5 & 870.25 & 36.26 \\
\hline
\end{tabular}

As shown in table 4, the value of the Chi-square obtained for the total use of dc-pairing patterns $\left(X^{2}=36.26\right)$ was far more than the critical value (3.84) with one degree of freedom $(d f=1, p<0.05)$; therefore, the difference between the two textbooks was meaningful. In other words, there was a significant difference between denial-correction pairing patterns used in the MA and the $\mathrm{PhD}$ textbooks in terms of the frequency of the use of the first three patterns. Therefore, the MA textbook writers were inclined to use the first three patterns four times (but not cases) more frequently than the PhD textbook did, normalized for 1000 sentences. This finding exhibited marked difference between the MA and
PhD corpora with regard to the use of the first three dcpairing patterns. On the other hand, it should be noted that although these patterns were relatively less frequently used in the PhD textbook in comparison to the MA counterpart, they were the very pairings which were by far the most frequent ones in the $\mathrm{PhD}$ textbook as well. In other words, the patterns in question made up the greatest part of the use of dc-pairings in terms of frequency of occurrence when the PhD textbook was considered independent of the other textbook. Overall, they comprised $77 \%$ and $54 \%$ of the occurrences of all the patterns in MA and PhD textbooks, respectively (See Table 5 below). 
Table 5. The comparison of the two groups in their use of the first three DC pairing patterns (Normalized for 1000 sentences) $P<.05$ d.f. $=1$.

\begin{tabular}{llllllll}
\hline & Denial-correction pairing & O for MA (\%) & O for PhD (\%) & E & (Fo-Fe-0.5) Yates Correction & (Fo-Fe-0.5) $^{\mathbf{2}}$ & $\sum(\mathbf{F o}-\mathbf{F e}-\mathbf{0 . 5})^{\mathbf{2}} / \mathbf{E}$ \\
\hline 1 & A rather than B & $38(37)$ & $8(24)$ & 23 & 14.5 & 210.25 & 18.28 \\
2 & A, not B & $24(24)$ & $5(15)$ & 14.5 & 9 & 81 & 11.17 \\
3 & not A, but B & $16(16)$ & $5(15)$ & 10.5 & 5 & 25 & 4.76 \\
\hline
\end{tabular}

Owing to the fact that the Chi Square obtained $\left(X^{2}=18.28\right)$ for the first pattern was far more than the critical value (3.84) with d.f. $=1$ at .05 level, we are confident that the data support the idea that there is a significant relationship between the educational level of the textbook and the frequency of selection of a particular dc-pairing. With regard to the first pattern (i.e., A rather than B), MA textbook was more likely to use the pattern than the $\mathrm{PhD}$ textbook (See Table 6 below).

Table 6. The comparison of the two groups in their use of pattern one: A rather than B (Normalized for 1000 sentences) P<.05 d.f. $=1$.

\begin{tabular}{|c|c|c|c|c|c|c|}
\hline Textbook & $\mathbf{O}$ & $\mathbf{E}$ & (Fo-Fe-0.5) Yates Correction & $(\mathrm{Fo}-\mathrm{Fe}-0.5)^{2}$ & $(\mathrm{Fo}-\mathrm{Fe}-0.5)^{2} / \mathrm{E}$ & Chi-square observed \\
\hline MA & 38 & 23 & 14.5 & 210.25 & 9.1 & \multirow{2}{*}{18.28} \\
\hline $\mathrm{PhD}$ & 8 & 23 & -14.5 & 210.25 & 9.1 & \\
\hline
\end{tabular}

The result of the data shows that the writer for MA textbook was relatively more aware of the student-reader's misconceptions, and therefore, recurrently referred to such misconceptions only to then correct them and lead the reader to focus on the correct side of the idea being discussed in the text. Providing the reader with both sides of the subject, denying the one which is false, and immediately presenting the correct one by using the dc-pairing, all enable the writer to construct knowledge which is contextually correct. That is, the writer is equipped with patterns that empower him/her to present that part of any idea which the particular discipline (Applied Linguistics) shows to be correct. Moreover, based on the discipline and the context in which the idea is presented, the reader comes to know what is false, thereby to avoid it, and also what is shown to be correct, and thereby to side with it. All this is possible through the context of situation and awareness of audiences' expectations in general, and the use of dc-pairing patterns in particular.

By the same token, for the second pattern (i.e., A, not B), Chi Square $\left(X^{2}=11.17\right)$ was far more than the critical value (3.84) with one degree of freedom $(d f=1, p<0.05)$; therefore, there was a significant difference between denialcorrection pairing patterns used in the $\mathrm{MA}$ and the $\mathrm{PhD}$ textbooks in terms of the frequency of the use of the second pattern (See Table 7 below).

Table 7. The comparison of the two groups in their use of pattern two: A, not B (Normalized for 1000 sentences).

\begin{tabular}{lllllll}
\hline Textbook & O & E & (Fo-Fe-0.5) Yates Correction & (Fo-Fe-0.5) $^{\mathbf{2}}$ & (Fo-Fe-0.5) $^{\mathbf{2}} / \mathbf{E}$ & Chi-square observed \\
\hline MA & 24 & 14.5 & 9 & 81 & 5.6 & 11.17 \\
$\mathrm{PhD}$ & 5 & 14.5 & -9 & 81 & 5.6 & \\
\hline
\end{tabular}

With regard to the third pattern as indicated in Table 1 above, (i.e., not A, but B), Chi Square $\left(X^{2}=4.76\right)$ was more than the critical value (3.84) with one degree of freedom $(d f$ $=1, p<0.05$ ); therefore, there was a significant difference between denial-correction pairing patterns used in the MA and the $\mathrm{PhD}$ textbooks in terms of the frequency of the use of the third pattern (See Table 8 below). Therefore, MA textbook tended to use the pattern more frequently than the $\mathrm{PhD}$ textbook. This is part of the answer to the third question in the current study.

Table 8. The comparison of the two groups in their use of pattern three: not A, but B (Normalized for 1000 sentences).

\begin{tabular}{lllllll}
\hline Textbook & O & E & (Fo-Fe-0.5) & Yates Correction & (Fo-Fe-0.5) $^{\mathbf{2}}$ & (Fo-Fe-0.5) $^{\mathbf{2}} /$ E \\
\hline MA & 16 & 10.5 & 5 & 25 & 2.4 & Chi-square observed \\
PhD & 5 & 10.5 & -5 & 25 & 2.4 & 4.76 \\
\hline
\end{tabular}

$\mathrm{P}<.05$, d.f. $=1 \mathrm{O}=$ observed, $\mathrm{E}=$ Expected, critical value $=3.84, X^{2}=\sum(\mathrm{Fo}-\mathrm{Fe}-0.5) 2 / \mathrm{E}=$ Chi-square observed

It was found that the $\mathrm{PhD}$ textbook was relatively less likely to use the pattern than the MA counterpart. Conversely, the MA textbook denied the false part of the idea first, then immediately provided the correct part, thereby could lead the reader to the correct part of the idea. Once again, although the two corpora frequently tended to make use of the same pattern, it was the MA textbook which tried to correct the presumed wrong assumptions of the readers more than the one for $\mathrm{PhD}$. This can be related to the fact that $\mathrm{PhD}$ audience is supposed to be more familiar with correct ideas. The number of dc-pairings based on the misconceptions of the specific audience is thus kept in low profile.

Noteworthy is the finding that there were two other dcpairing patterns in the corpus, one was a stylistic variation for Pattern 2 in which metediscourse markers in the form of punctuation marks accounted for one member of the pattern. That is to say, a comma, or semicolon replaced the use of but or rather than which preceded the denial introduced by not, 
and corrected the other part of the idea in the pairing. Such a stylistic variation was instantiated by Pattern 10 as used in MA textbook only. On the other hand, a stylistic variation to Pattern 8 (not A; B) was Pattern 11 (not A, B) which were scantly used in both MA and PhD textbooks, though Pattern 8 was slightly more frequent than Pattern 11. This variation was mainly based on punctuation as a metadiscourse marker in the texts.

With regard to metadiscourse, Williams (1981) [23] defines it as " ... writing that guides the reader, ... informs the reader about primary topics ... discourse about discourse" [23]. Moreover, Hyland (2000, 2004) [10] [11] states that metadiscourse [13] enables a writer to produce a well-formed, coherent and reader-friendly text, to relate it to a given context, and to convey his or her credibility, audience awareness and relationship to the message. Metadiscourse, accordingly, reveals the writer's awareness of the audience and his/her need for guidance, elaboration and clarification.

In constructing meaning through communicative acts with the audience, the degree of knowledge overlap between writer and reader is very crucial [12]. Hyland argues that writing for oneself permits a lot to be left unsaid, whereas in writing for a largely unknown audience it is often required to be more explicit, exploiting lots of rhetorical devices to assist readers to understand the material. That is, a writer needs to talk to readers in such a way that they find the message acceptable and appropriate. Additionally, in written texts various forms of punctuation and typographical marks such as underlining, capitalization, scare quotes and exclamation marks can highlight aspects of a text or the writer's attitudes to it [12]. Therefore, as found in the corpus, punctuation as one form of metadiscourse markers, can be part of a dcpairing. In this regard, comma, or semicolon mainly conveyed the meaning of but, rather. In the following examples, semicolons convey the meaning of but or rather:

(37) The terms principles and procedures are not new; they are implicit in the literature and are being used widely though not uniformly or consistently [14].

(38) L2 education is not a discrete activity; it is deeply embedded in the larger social context that has a profound effect on it [14].

An additional function conveyed by dc pairings is that of emphasis. Through the dc pairing, the writer emphasizes the correct part and firmly rejects the false element in the idea as in:

(39) "TBLT focuses on learning by doing and takes the position that tasks, not skills, are the unit of analysis" (italics in the original) [15]. Here, the correct idea precedes not, and is also italicized. Moreover, the false element (i.e., skills) follows the negator not. And the idea that the unit of analysis are just tasks and no other things is emphasized both typographically and through the use of the dc pairing. Yet another example from the $\mathrm{PhD}$ corpus is:

(40) “... found delayed, but not immediate effects for adults" [15]. It is evident that immediate is in antonymy relation with delayed, yet it is used to give emphasis to the idea presented with delayed, so that the unexpectedness of the effect is highlighted.

Further scrutiny into the corpus to find out the functions of dc-pairing patterns revealed that the pairing can at times be used when it is important to talk about the issue at stake more accurately. One of the most revealing examples is the following sentence from the MA corpus:

(41) “... classroom contexts have often, but not always, zeroed in on corrective feedback ..." [15], where usuality as a subcategory of modalization [7] is delimited to precisely encompass the correct term of usuality (i.e., often) rather than the all-encompassing word of usuality indicated by always. In other words, it is the dc-pairing (among other words in the context) that indicates the existence of exceptions to the case, as it is something that happens often rather than always.

As defined in Collins Co-build Advanced Dictionary of English (2015) [4], rather than as a phrase conjunct is used "when you are contrasting two things or situations. It introduces the thing or situation that is not true or that you do not want." The denial-correction pattern with rather than contrasts two (parts of) ideas, concepts, or parts of one idea; denies one of the two parts just on the basis of the context and the discipline, and immediately presents the correct counterpart. That which part is to be denied is based on the ideas developed in the discipline. By the same token, what determines the correctness of the idea presented by the pattern is also dependent upon the specific context in which it is used, the evidence or rationale given in the text, and the development made in the (sub) discipline. For instance, a 1960's mentality as in Bloomfield (1942), would agree with behaviorism that would conceive of "language learning [as] just a process of mechanical habit formation through repetition" [14] as a correct statement. However, because of the development in the field, such an idea is refuted and is replaced by cognitive processes and socio-cultural mechanisms in social constructivism. Therefore, learning has been conceived of as a socio-cultural mechanism rather than a process of habit formation. On the other hand, although it is Chomsky's idea among others that has challenged behaviorism and thereby the writer has denied the false behavioristic definition of learning, what is advocated by Chomsky as the correct idea, however, is also refuted by a later development in the field. This time, the denialcorrection pattern presents the correct part and simultaneously denies the very part that had previously been accepted as true. In other words, "Instead of viewing language as something exclusively internal to the learner, as Chomsky does, Halliday (1973) views it as a means of functioning in society" [14]. Halliday's idea is (for the moment) relatively more developed than that of Chomsky's [14]. Therefore, the writer uses the better ideas constructed by the development in the field and refuses what is now considered as false and states that: Chomsky (1959), is interested in looking at human language as a cognitive psychological mechanism rather than as a communicative tool for social interaction.

As is evident in the examples, the piece of information favored by the discipline (i.e., Applied Linguistics) precedes 
the pattern while the unfavorable part follows it. Interesting to note is the fact that what determines the place of either the wrong or the correct piece, is just the specific context in which it is used. In other words, denial-correction pairings are context-dependent. Moreover, what is presented in the previous phase of the text may lead the reader to an incorrect conclusion; therefore, for solidarity with putative reader, the writer tries to deny the anticipated but wrong conclusion and also provide the reader with what is correct. With such an anticipation and intention in mind, the writer uses a dcpairing as in: "these ... distinctions should be viewed not as dichotomous but rather on a continuum" [15]. Furthermore, as Pagano (2004) [18] showed, what is rejected is made explicit. The discarded options are usually added to the text because "they are significant to the discussion of the topic" [18]. It is through denials added to the text that the misleading parts in the text and the wrong inferences are cancelled This is important, "because the option denied represents a disadvantage" [18] and what is offered as the correction is in contrast with it and is also advantageous.

\section{Conclusion}

The primary focus of the current study was the search for the patterns of denial-correction pairing in a corpus of MA and $\mathrm{PhD}$ textbooks in Applied Linguistics written by native speakers of English and taught by professors in Iranian universities for the two high levels (MA, PhD) at tertiary education in Iran. The quest for dc-pairings revealed 12 patterns which were frequently used in the corpora. The 12 patterns contained both denial and correction juxtaposed with each other. Of these patterns, three were the most frequently occurring patterns in the corpora. Two were just specifically used in the MA textbook, whereas one other pattern was uniquely used in the $\mathrm{PhD}$ textbook. There was a significant difference between denial-correction pairing patterns used in the MA and the PhD textbooks in terms of the frequency of the uses of the patterns. Therefore, the MA textbook tended to use the patterns more than the $\mathrm{PhD}$ one. That is, the MA textbook opted for more denial and correction that would guide the audience (i.e., students majoring in AL) to the correct part of the ideas.

In dc-patterns, it was found that although there were stylistic variations through the use of punctuation as metadiscourse markers, the writers provided two sides of an idea, evaluated them, thereby denied what was considered as false and immediately presented the correct one. Therefore, the writers guided the readers towards the correct ideas and removed the misconceptions. Moreover, this showed the writer as the one who had more expertise in the field. The patterns were also used as devices to emphasize the falsehood of one and correctness of the other part of the idea in the pattern. Additionally, when it was necessary to express ideas relatively more precisely, these patterns were aptly used as one of the best options in academic discourse. And finally, although denial-correction is heteroglossic; that is, it construes a dialogistic backdrop for the text of other voices and value positions, it is maximally contractive as it excludes certain dialogic alternatives. This means that, via the denial the dialogic alternative is directly rejected, replaced or "held to be not applicable" [16]. In other words, it is heteroglossic in that it considers at least two alternatives for the issue at stake and construes a dialogistic backdrop for the text of other voices. On the other hand, it is contractive rather than expansive, as it denies one alternative and presents the other as the sole part which is correct. It thus closes the space and leaves no room for any other alternatives. Therefore, denialcorrection pairings are heteroglossic, and dialogistically contractive.

From a metafunctional perspective, the interaction between writer and reader builds the interpersonal function [18]. In addition, ideationally, the correction accompanying the pairing adds a correct piece of information to the discourse as well as interpersonally leading the reader to what is contextually correct. Moreover, it is the dc-pairing as a lexico-grammatical pattern that construes the textual function which is "the linguistic realizations of the ideational and interpersonal functions" [14] that enable the writer to construct a coherent written text, which is correct due to being based on the knowledge constructed in the discipline and the specific context of use.

A further finding of the current study is in consonance with Pagano's statement that when some idea in the text is likely to lead the reader to a wrong interpretation [18], it is the dcpairing that enables the writer to clarify it via a very economic device in which the false element is presented as a denial and the correction to it is immediately given. In other words, the denial and the correct idea are economically put in a nutshell realized through the dc-pairing patterns.

This is evident in all the 12 patterns revealed through the study. Noteworthy is the fact that what is denied can be the reader's misconception prior to the act of reading the text; an unfulfilled expectation exposing the limitation of a study (e.g., the book discusses Psycholinguistics and not Sociolinguistics, so do not expect the latter issues to be covered in the book); and the reader's misinterpretation of a phase of a text based on reading the very text. The idea denied can also be a specific one (e.g. in academic writing), which only those who are familiar with the basic assumptions and theories of the specific area can actually have, as they belong to the community which sustains those ideas [18]. The dc-pairing patterns are all the loci for the writer of entering into the text so as to mark all the false parts, provide the reader with the correction to the denial (i.e., the false element), and show the writer's more expertise in the specific issue at stake and also the discipline. The reader, thus, not only "learns about the other members of the existential paradigm which they consider wrong" [18] but gets to know what is acceptable in the field as well. Therefore, the pairings are of crucial importance and of great use to both the writer to present the idea and to the reader to put the false parts aside and learn and follow the correct parts while interacting with the issues in the text. In other words, the reader comes to know the false element, puts it aside as it is denied by the 
writer, and is immediately given the correct element, thereby, follows the writer's lead construed through the dc-pairing patterns.

In line with Pagano's conception of denials (2004) [18], as the writer of the textbook "anticipates ... the reaction that his words may produce" [18] in his audience (students majoring in $\mathrm{AL}$ at MA or PhD levels) he denies what he/she believes the audience will think about and immediately provides the correct interpretation, element, or piece of information needed. Such provision of information is never delayed as the patterns are the juxtaposition of the denials and corrections in a pairing. That is, the patterns are not just denials, but contain the correction to what is just denied. Therefore, the readers are not left alone with a false idea that is denied. Instead, they are engaged in what is contextually correct in the discipline.

The MA textbook used the dc-pairing patterns relatively more frequently than the $\mathrm{PhD}$ counterpart. It is concluded that since the level of MA audience is different from that of the $\mathrm{PhD}$, the there is a tendency in the writer of the MA textbook to guide the putative student reader more frequently than that of the $\mathrm{PhD}$ audience, who is by definition supposed to be more familiar with and attentive to the ideas in the discipline, though there can be fluctuations in the general outlook. In other words, from a functional perspective, the interpersonal function is so important for the MA writer that, the putative reader's misconceptions are denied and immediately corrected. Moreover, the ideational meaning has to contain the correct one, and if there is a false misconception prior to reading the text, a wrong inference based on the same text, or a wrong counterpart in the ideas presented in a phase of the textbook, it is to be revealed, uttered, denied and immediately corrected, as this crucial move, whenever needed, had been done in all the cases in this study via the use of dc-pairing patterns.

It is necessary for a textbook designed to be studied at the higher levels of education to provide the audience with every relevant part of an idea, refute some, rebut others, and when it is narrowed down to two final components, one of which is of dubious state, consider it thoroughly, reveal the wrong one, and deliver the correct part to finally construct knowledge in the field. To this end, one of the most frequent strategies used by the writers was the use of denial-correction pairings. The patterns can be used for two terms, notions, two elements within a system, two parts of the same idea, two opposing ideas, two schools of thought, and even two eras of human endeavor in exploring the discipline. From all this, the two counterparts are presented through the dc-pairing patterns so that one is denied and the other counterpart is immediately exhibited as the correct one. Both the denial and the correction are supported by further evidence and argumentation in the immediate text and context. Although it is sometimes the case to deny one part outright (following the negator not for denial), the text goes on providing evidence, or logical statements to completely support the correctness of the idea presented as the correct part in the pairing. The study revealed that the falsehood and correctness of the two parts of a pairing absolutely depend on both the discipline and the context in which the pattern is used.

Contrary to what both Pagano (2004) [18] and Winter (2004) [24] hold to be the case concerning the only function of dc-pattern they had found, there are cases where the elements that occupy A or B slots in a dc-pairing pattern, are both correct. That is, there is no false part to be corrected within the pattern. For instance, a case in point is the following sentence from the $\mathrm{PhD}$ corpus, where both close and open tasks are pedagogically well-founded, and correct. However, it is the specific context in which close and open are used that determines one to be more favorable than the other. Therefore, one element is considered unexpected and unfavorable whereas the other is accepted as being the case: "... this modification makes the task closed rather than open" [15]. It is possible for a task to be closed or open, and both can be favorable. Yet suitability for a task is not assigned by the grammatical position of the words closed/open; that is, they may precede or follow the pattern, and no member of the specific discourse community (Applied Linguistics, here) can claim closed or open as false. Rather, it is the context that determines whether closed or open is favorable. Based on the context, in this example, closed was favorable and not open.

\section{References}

[1] Bakhtin, M. M. 1981. The dialogic imagination (translated by C. Emerson \& M. Holquist) Austin: University of Texas Press.

[2] Brazil, D. (1985). The communicative value of intonation in English, Discourse Monographs No. 8, Birmingham: University of Birmingham.

[3] Cohen, G., Eysenck, M. W., \& Le Voi, M. E. (1986). Memory: A cognitive approach. Philadelphia: Open University Press.

[4] Collins Cobuild Advanced Dictionary of English. (2015). Harper Collins Publishers.

[5] Connor, U., \& Mauranen, A. (1999). Linguistic analysis of grant proposals: European union research grants. English for Specific Purposes 18 (1), 47-62.

[6] Eggins, S. (2004). An introduction to systemic functional Linguistic. New York: Continuum International Publishing Group.

[7] Halliday, M. A. K. (1994). An introduction to functional grammar. London: Edward Arnold.

[8] Halliday, M. A. K. \& Matthiessen, C. M. I. M. (2004). An introduction to functional grammar. London: Hodder Arnold.

[9] Hatch, E., \& Farhady, H. (2007). Research design and statistics for applied linguistics. Tehran: Rahnama Publications.

[10] Hyland, K. (2000) Disciplinary discourses: Social interactions in academic writing. London: Longman.

[11] Hyland, K. (2004). Disciplinary interactions: Metadiscourse in L2 postgraduate writing. Journal of Second Language Writing 13: $133-151$. 
[12] Hyland, K., (2005). Metadiscourse: Exploring interaction in writing. New York: Continuum.

[13] Hyland, K. and Tse, P. (2004). Metadiscourse in academic writing: a reappraisal. Applied Linguistics, 25 (2), (pp. 15677).

[14] Kumaravadivelu, B. (2008). Understanding language teaching: From method to post-method. Mahwah, New Jersey: Lawrence Erlbaum Associates.

[15] Mackey, A. (2012). Input, interaction and corrective feedback in L2 learning. Oxford: OUP.

[16] Martin, J. R. \& White, P. R. R. (2005). The language of evaluation: Appraisal in English. New York: Palgrave Macmillan.

[17] Miller, G. \& Johnson-Laird, P. (1976). Language and perception, Cambridge: CUP.

[18] Pagano, A. (2004). Negatives in written text. In M. Coulthard (Ed.). Advances in written text analysis (pp. 250-265). New York: Routledge.
[19] Poutsma, H. (1926). A grammar of late modern English. Groningen: Nordhoff.

[20] Tottie, G. (1982). Where do negatives come from? Studia Linguistica 36/1, (pp. 88-105).

[21] Tottie, G. (1987). Rejections, denials and explanatory statements - a reply to Fretheim, Studia Linguistica 41/2, (pp. 154-63).

[22] Widdowson, H. G. (1979). Explorations in applied linguistics. Oxford: Oxford University Press.

[23] Williams, J, M. (1981). Style: Ten lessons in clarity and grace. Chicago: University of Chicago Press.

[24] Winter, E. O. (2004). Clause relations as information structure: Two basic text structures in English. In $\mathrm{M}$. Coulthard (Ed.). Advances in written text analysis (pp. 46-68). New York: Routledge. 